\title{
LOW LeVel Laser Therapy as AdJUnGTive SUPPORT IN IMPLANT DENTISTRY: A RELIABLE OPTION?
}

\section{Terapia láser de baja potencia como apoyo complementario en la implantología: ¿una opción fiable?}

\author{
SARA Bernardi (1) \\ Department of Life, Health and Environmental Sciences, University of L'Aquila Italy. \\ sara.bernardi@univaq.it
}

\begin{abstract}
ABSTRAGT
Use of low level laser therapy (LLLT) in bone healing has been studied for years, and its application in implant dentistry is still a controversial topic due to the difficult assessment of its clinical efficacy. We report the application of LLLT as aid in the osseointegration in two patients undergone to implant surgery in the upper jaw. In one hemi-arch the LLLT was applied and the other one was used as control. The assessment of the bone area surrounding the fixtures was performed by means of cone beam compute tomography and the area of bone-implants contact was measured by means of InVesalius ${ }^{\circledR}$ software. The radiological findings support the idea of considering the laser biostimulation as an adjunctive aid in implant surgery.
\end{abstract}

Keywords: photobiostimulation; implant dentistry; laser therapy.

\section{Introduction}

Laser technology is nowadays a daily therapy instrument used in all of the dental branches (Tunér and Beck-Kristensen, 2011; Bernardi et al., 2016). Among the well-known effects of the laser beam interaction with biological tissues, the photobiomodulation or biostimulation refers to lasers ability to speed healing, increase circulation, reduce edema, and minimize pain (Jacques, 1992).

The impropriate name Low level laser therapy (LLLT) is defined as the use of laser at a low power (1 watt usually) at wavelength ranging from $623 \mathrm{~nm}$ to $1064 \mathrm{~nm}$ (Vescovi et al., 2007) to induce the stimulation of the natural healing processes. However, the last editorials by Anders et al., proposes a new and clearer name of this type of therapy: Photobiomodulation Therapy (Anders et al., 2019). Indeed, the biological effect is induced not by the power emitted from the machine, but the power that reach the targeted tissues (Anders et al., 2019). The results claimed by the photobiomodulation therapy 
include biochemical, bioelectric and bioenergetic changes in the tissue environment. These changes consequently increase the metabolism, induce the cell proliferation (Jacques, 1992).

When an inflammatory process is running, there is a consequent reduction of inflammatory molecules with an improvement of the healing process (Avci et al., 2013). Indeed, inflammatory process include the promotion of regeneration of traumatized tissues by means of specific proinflammatory mediators, including prostaglandins, and lipoxins which are the products of arachidonic acid metabolism (Plaetzer et al., 2009).

It is reported that at molecular level, the absorption of laser light increases the cellular metabolism, stimulating the chromophores in the mitochondrial respiratory chain, with changes in cellular Adenosine TriPhosphates (ATP) levels, releasing growth factors, and improving the synthesis of collagen (Nicola et al., 2003).

The anti-inflammatory and anti-edema effects are achieved by means of the acceleration of microcirculation. Consequently, the capillary hydrostatic pressure changes with edema reduction (Avci et al., 2013).

Hence, at tissue-level there is an induction of mitotic activity of epithelial cells and fibroblasts, stimulation of collagen production by those cells, inhibition of secretion of some chemical mediators, changes in capillary density and stimulation of local microcirculation (Basso et al., 2012).

Clinically, the mentioned laser therapy has been used for treatment of oral pathology lesions such as aphthous ulcers, herpes labialis lesion paresthesia, mucositis, biphosphonate related osteo necrosis of the jaws (Rood, 1992; Walsh, 1997; Vescovi et al., 2007; Albrektson, Hedstrom and Bergh, 2014; Oton-Leite et al., 2015).

In this context, the possible application of the photobiomodulation therapy in the bone regeneration and in implant osteointegration seems very appealing.

Indeed, the bone regeneration techniques have been developed in dentistry also with the aim of providing enough volume of alveolar bone capable to support and implant insertion and integration of implant fixtures.

Hence, the use of an adjunctive protocol to speed and improve the bone healing process seemed to be very promising in the branch of implant dentistry.

Earlier studies in vitro and in vivo (Tang and Arany, 2013) show the benefits from using this therapy on peri-implant tissues, but only few clinical trials reported the benefits of this technique.

The aim of this paper is to report the clinical evaluation of the effective benefits of this therapy in implant surgery.

\section{Case Reports}

\section{Biostimulation Protocol}

The biostimulation protocol, set according the data available in literature (Lancieri et al., 2011), included the use of a Nd-Yag laser (SmartFile, Deka M.E.L.A., Italy), with a length wave of $1064 \mathrm{~nm}$, setting the power at 1.00 Watt, the energy at $100 \mathrm{~mJ}$, and the time at 60". The applied optical fiber was $600 \mathrm{~mm}$ type and easily applicable it in the fornix. The treatment was applied at T0 (set as the day of the intervention) and at the $3 \mathrm{rd}$, the 5 th and the 7 th day. In order to minimize the eventual systemic effect (Fronza et al., 2013), the two interventions were performed in two times, treating surgically at 
first the quadrant used as control. The biostimulation was performed by the same dentist to minimize any inter-operator bias.

\section{Digital measurements}

Due to the relative low invasiveness of CBCT (Bernardi et al., 2016), the radiological method was used to assess any difference at the follow-up. After importing the DICOM files, the bone contact area around each implant was segmented and the related measurements were noted.

\section{Case 1}

The selected no-smoker patient, with a previous dental history of chronic periodontitis, needed to restore by the implant therapy the edentulous posterior maxilla. From the cone beam computed tomography (CBCT), due to the few available volumes of bone on both sides, a contextual sinus lift floor with grafting materials and with the implant placement was planned (Figure 1 a). Specifically, three implants in 1.4., 1.5 and 1.6 position and on 2.4, 2.5 and 2.6 positions. Since the patient needed to restore both sides of posterior maxilla, we could use it as self-control, treating first quadrant with the laser therapy and not treating the second quadrant.

After the surgical intervention, a Ketoprofene therapy was added, and the ice was applied on the treated zone. Soon after the patient was processed by the biostimulation protocol (Figure $1 \mathrm{~b}$ ), repeated at the third, the fifth and the seventh day from the intervention.

The irradiated area corresponded to the region from 1.4 to 1.6. The assessment of the effective benefit of the treatment was performed at the 4th month follow up, using CBCT. The volume of bone contact was measured by means of InVesalius ${ }^{\circledR}$ software, which allows the volume measurement on DICOM images (Figure 2).

At the fourth month follow-up, the segmentation performed on the CBCT volumetric reconstruction (Figure 5) showed an area of bone contact with the surface implant of $442 \mathrm{~mm}^{2}, 459 \mathrm{~mm}^{2}$ and $446 \mathrm{~mm}^{2}$ respectively on the implants in position 1.4, 1.5 and 1.6. The volumes of the control side resulted to be 428 $\mathrm{mm}^{2}, 445 \mathrm{~mm}^{2}$, and $429 \mathrm{~mm}^{2}$ respectively on the implants in position 2.4, 2.5 and 2.6.

\section{Figure 1.}

(a) Panorex reconstruction derived from the CBCT. The available bone is not suitable for the implant placement on both maxillary arches. In the mandible, the treatment plan included the extraction of the unhealthy elements. (b) Laser application in the vestibular fornix.

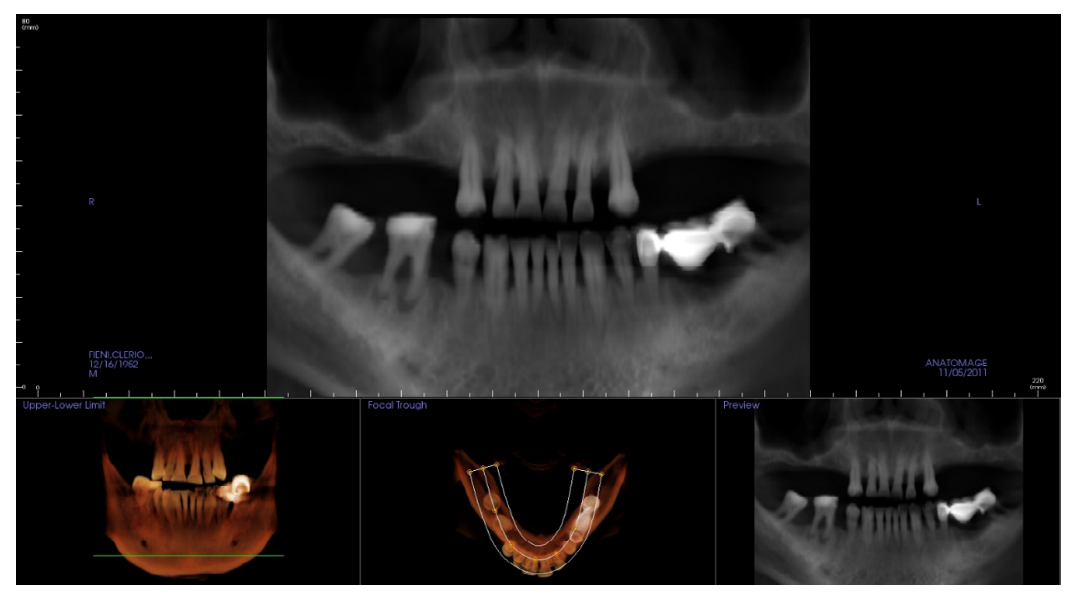

(a)

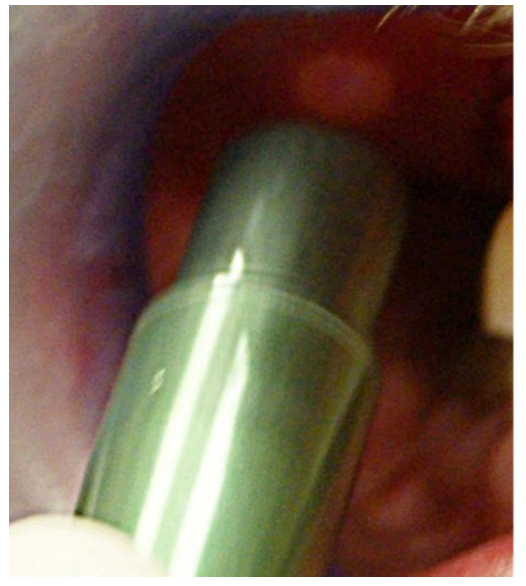

(b) 
Figure 2.

Volume reconstruction with the segmentation of the bone area in contact with the implant surfaces. The scattering of the implants did not allow to measure the proximal areas of the bone. Volume rendering obtained using InVesalius ${ }^{\circledR}$ software.

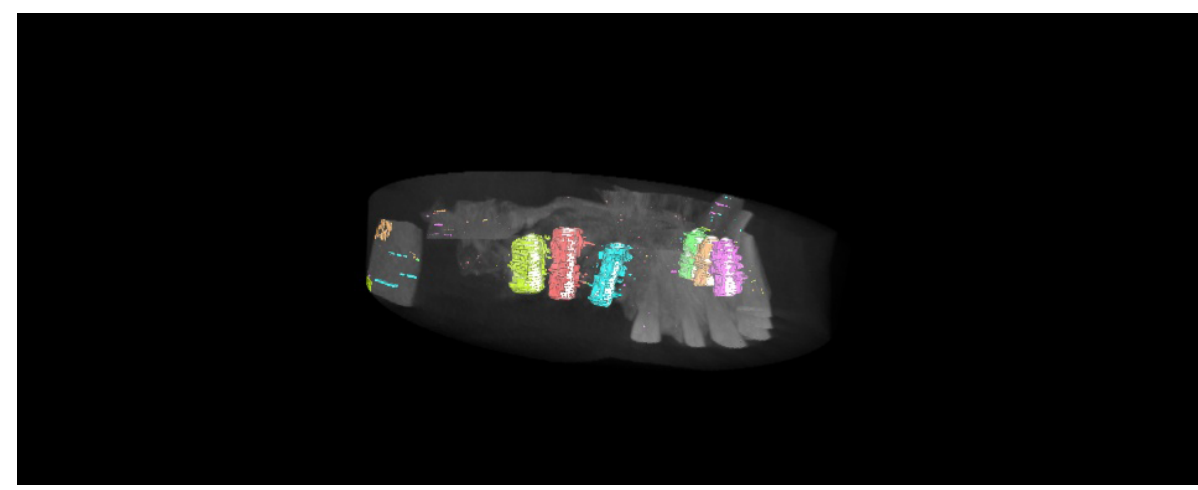

\section{Case 2}

As the first case, the selected no-smoker patient, with a previous a previous dental history of chronic periodontitis needed to restore by the implant therapy the edentulous posterior maxilla. From the cone beam compute tomography (CBCT), due to the few available volume of bone on both sides, a contextual sinus lift floor with grafting materials and with the implant placement was planned. Specifically, the plan treatment included the need to place an implant in position 2.6 and three implants in 1.4., 1.5 and 1.6 position (Figure 3a). The site selected for the irradiation was the 2.6 and the 1.6 was considered as the control in the evaluation stage. After the surgical intervention, a Ketoprofene therapy was added, and the ice was applied on the treated zone. Soon after the patient was processed by the biostimulation protocol (Figure 3b), repeated at the third, the fifth and the seventh day from the intervention.

The assessment of the effective benefit of the treatment was performed at the 4th month follow up, using CBCT. The volume of bone contact was measured by means of InVesalius ${ }^{\circledR}$ software, which allows the volume measurement on DICOM images (Figure 4).

At the fourth month follow-up, the segmentation performed on the CBCT volumetric reconstruction (Figure 6) showed a volume bone contact with the surface implant of $509 \mathrm{~mm}^{2}$ on the biostimulated site and of $574 \mathrm{~mm}^{2}$ on the selected control site (1.6). 
Figure 3.

(a) Panorex reconstruction derived from the GBCT. The available on the second quadrant is not suitable for the implant placement. Both maxillary edentulism required a fixed rehabilitation.

Overall, the bone level on the remaining dental elements shows signs of health condition. (b) Laser application in the vestibular fornix.

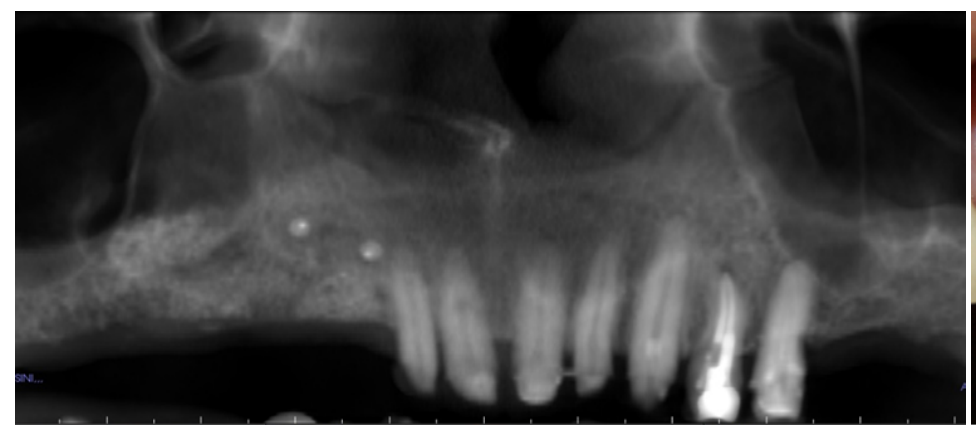

(a)

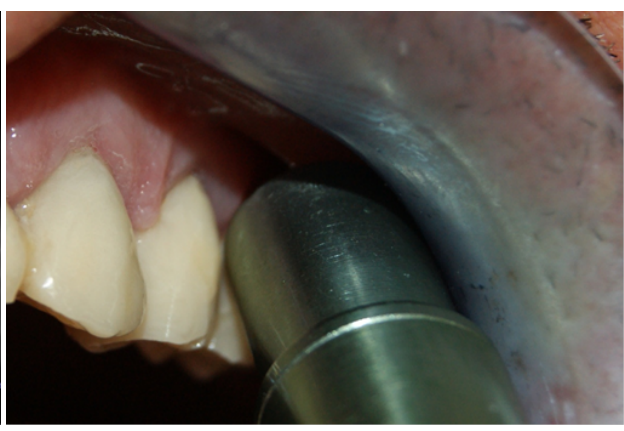

(b)

Figure 4.

Volume reconstruction with the segmentation of the bone area in contact with the implant surfaces. The scattering of the implants did not allow to measure the proximal areas of the bone. Volume rendering obtained using InVesalius ${ }^{\circledR}$ software.

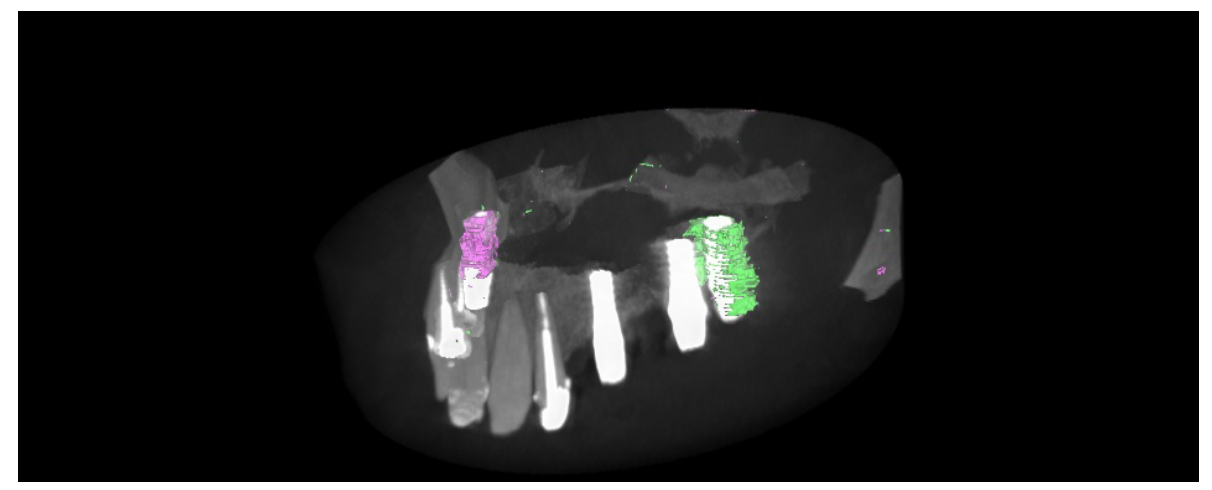

\section{Discussion}

Tooth loss for any reason is a trauma for the alveolar bone and maybe represent a psychological factor affecting the quality of life of patients (Øzhayat et al., 2016).

Indeed, edentulism is a not life -threating condition but can influence the daily lifestyle of a patient. For extended edentulisms the therapy solution such as removable prosthesis is a low risk and reliable option, but sometimes the discomfort due to the mobility of the device is not appreciated by patients (Falisi et al., 2017).

The biostimulating laser effect on the osteoblasts to accelerate the dental implant osteointegration is still a controversial topic. From earlier studies, laser biostimulation seemed to be a valid support in the healing of the bone fractures and in vitro and in animal model the results were promising. Indeed, in 1987 Trelles e Mayayo, reported the healing of the bone fractures in a mouse model, 
with neo-vessels and bone trabecular formation after three weeks of daily irradiation (Trelles and Mayayo, 1987).

In 1990 Abe used LLLT as treatment of a pathologic fractures, suggesting this therapy could be used as non-invasive and efficient tool (Abe, 1990).

Dörtbudak et al. firstly in an in vitro study using osteoblasts and chondrocytes, confirmed the positive effect of LLLT on cellular growth and differentiation (Dörtbudak et al., 2000). The same group of work continued the research using babbons model: the cellular counts and the peri-implant bone resorption were observed in the iliac crest of male baboons after implant insertion into each iliac crest of the primates (Dörtbudak, Haas and Mailath-Pokorny, 2002). In this study they showed the laser irradiation improve the number of vital osteocytes in the irradiated bone (Dörtbudak et al., 2002).

In 2003 Guzzardella et al. in their in vivo study on animal, evaluated how the low power laser irradiation can improve the biomaterial osteo-integration (Guzzardella et al., 2003). They tested cylindrical hydroxyapatite implants placed in rabbits' femurs; the histomorphometry analysis performed showed a higher affinity index at the interface bone-implant in the irradiated group than in the control group (Guzzardella et al., 2003).

In 2004 Khadra et al. evaluated the diode laser low power application on the healing and osteointegration quality; the histological analysis showed a better bone-implant interface in the irradiated group. In addition, the tensile test on the strength distribution was performed (Khadra $e t$ al., 2004). It showed a gain of the functional bone attachment on the implant surfaces in the irradiated sites (Khadra et al., 2004).

In 201 1, Lancieri et al. in their case-control study, applied the laser biostimulation for the integration of biomaterial in case of ridge-preservation socket, reporting promising results both clinically and histologically (Lancieri et al., 2011). New dense lamellar bone, normal bone marrow and a great deal of active new bone formation were noted (Lancieri et al., 2011).

However, the recent systematic review of Noba et al, highlighted the weak of evidence of an effective influence of oral healing due to the laser biostimulation (Noba et al., 2018).

Indeed, there is a lack of a standardized protocols and of enough randomized clinical trials to assess the efficacy of this adjunctive therapy in oral surgery.

Even though the experimental animal model showed positive results, the studies with a methodological design with a low bias risk were only a few and therefore the strength of the biostimulation effect in oral surgery procedures is still low and needed to be further investigated.

The cases reported, evaluated by a limited radiological point of view and far from claiming the efficacy of the photobiostimulation, questioned its reliability. As the measures showed, in the first case, there was a little gain in the irradiated sites, instead in the second case the implant site biostimulated did not show any difference with the control site. However, the biomaterial used for the sinus lift appeared to be well integrated.

\section{Conclusions}

The photobiostimulation medicine represents a very promising therapeutic option to speed the bone healing after oral surgery procedures, including the implant placement. However, the strength of its reliability must be further investigated together with an established protocol. 


\section{Funding:}

This research received no external funding.

\section{Ethics:}

The photobiostimulation protocol was performed with the written informed-consent of the patients, and with no additional cost to the therapy, included the CBCT follow-up. Patients gave their permission to publish the data.

\section{Conflicts of interest:}

The authors declare no conflict of interest.

\section{Acknowledgment:}

Author would like to dedicate the present work to her family members. In addition, the case has been presented as poster in 2013 at the "PREMIUM DAY, 12th International Congress on Implant Prosthodontics, June 6th - 8th, 2013, Padova, Palazzo della Ragione, Italy" (Bernardi and Continenza, 2013).

\section{References}

Abe T. (1990) Diode Laser Lllt-Enhanced Bone Fusion Of Femoral Shaft Fracture Complicated By Chronic Osteomyelitis: A Case Report, Laser Ther, 2(4), pp. 175-178. https://doi.org/10.5978/ islsm.90-SC-0 1

Albrektson M., Hedstrom L. and Bergh H. (2014) Recurrent aphthous stomatitis and pain management with low-level laser therapy: a randomized controlled trial, Oral Surg Oral Med Oral Pathol Oral Radiol, 117(5), pp. 590-594. https://doi.org/10.1016/j.oooo.2014.01.228

Anders J. J. et al. (2019) Light-Emitting Diode Therapy and Low-Level Light Therapy Are Photobiomodulation Therapy, Photobiomodul Photomed Laser Surg, pp. 63-65. https://doi. org/10.1089/photob.2018.4600

Avci P. et al. (2013) Low-level laser (light) therapy (LLLT) in skin: stimulating, healing, restoring., Semin Cutan Med Surg, 32(1), pp. 41-52. http://www.ncbi.nlm.nih.gov/pmc/articles/pmc4126803/

Basso F. G. et al. (2012) In vitro wound healing improvement by low-level laser therapy application in cultured gingival fibroblasts., Int J Den , p. 719452. https://doi.org/10.1155/2012/719452

Bernardi S., Mummolo S., Ciavarelli L. M., et al. (2016) Cone beam computed tomography investigation about the antral artery anastomosis in a center of Italy population, Folia Morphol (Warsz), 75(2), pp. 149-153. https://doi.org/10.5603/fm.a2015.0095

Bernardi S., Mummolo S., Zeka K., et al. (2016) 'Use and Evaluation of a Cooling Aid in LaserAssisted Dental Surgery: An Innovative Study.', Photomedicine and laser surgery, 34(6), pp. 258-62. https://doi.org/10.1089/pho.2015.4008 
Bernardi S, Continenza MA. Bone Laser Biostimulation Applied to Implant Dentistry: a case report in Abstracts of the Pre-Congress Courses from the 12th International Congress on Implant Prosthodontics. June 6- 8, 2013. Padova, Palazzo della Ragione, Italy. Clinical oral implants research. 2013; 1-29

Dörtbudak O., Haas R. and Mailath-Pokorny G. (2002) 'Effect of low-power laser irradiation on bony implant sites.', Clin Oral Implants Res, 13(3), pp. 288-292. https://doi.org/10.1034/j.16000501.2002.130308.x

Dörtbudak O., Haas R. and Mallath-Pokorny G. (2000) Biostimulation of bone marrow cells with a diode soft laser., Clin Oral Implants Res, 11(6), pp. 540-545. https://doi.org/10.1034/j.16000501.2000.011006540.x

Falisi G. et al. (2017) "All on short" prosthetic-implant supported rehabilitations., Oral Implantol (Rome), 10 (4), pp. 477-487. En: https://www.ncbi.nlm.nih.gov/pmc/articles/PMC5892663/

Fronza B. et al. (2013) Assessment of the systemic effects of low-level laser therapy (LLLT) on thyroid hormone function in a rabbit model, Int J Oral Maxillofac Surg, 42(1), pp. 26-30. https://doi. org/10.1016/j.ijom.2012.06.017

Guzzardella G. et al. (2003) 'Osseointegration of endosseous ceramic implants after postoperative low-power laser stimulation: an in vivo comparative study.', Clin Oral Implants Res, 14(2), pp. 226-232. https://doi.org/10.1034/j.1600-0501.2003.00872.x

Jacques S. L. (1992) 'Laser-tissue interactions: Photochemical, photothermal, and photomechanical', Surg Glin North Am, 72(3), pp. 531-558. https://doi.org/10.1016/S0039-6109(16)45731-2

Khadra, M. et al. (2004) 'Low-level laser therapy stimulates bone-implant interaction: An experimental study in rabbits', Clin Oral Implants Res, 15(3), pp. 325-332. https://doi.org/10.1111/j.16000501.2004.00994.x

Lancieri L. et al. (2011) 'A new bone surgical laser technique: technical aspects and applications in dentistry', Front Biosci (Elite Ed), E3(January 1), pp. 463-468. http://doi.org/10.2741/e261

Nicola R. A et al. (2003) Effect of low-power GaAlAs laser (660 nm) on bone structure and cell activity: an experimental animal study., Lasers Med Sci , 18(2), pp. 89-94. https://doi.org/10.1007/ s10103-003-0260-z

Noba C. et al. (2018) Laser for bone healing after oral surgery: systematic review., Lasers Med Sci, 33(3), pp. 667-674. https://doi.org/10.1007/s10103-017-2400-x

Oton-Leite A. F. et al. (2015) 'Effect of low-level laser therapy on chemoradiotherapy-induced oral mucositis and salivary inflammatory mediators in head and neck cancer patients.', Lasers Surg Med, 47(4), pp. 296-305. https://doi.org/10.1002/1sm.22349

Øzhayat E. B. et al. (2016) Patients' experience of partial tooth loss and expectations to treatment: a qualitative study in Danish and Swedish patients., .J Oral Rehabil . 43(3), pp. 180-189. https:// doi.org/10.1111/joor.12355

Plaetzer K. et al. (2009) Photophysics and photochemistry of photodynamic therapy: fundamental aspects. Lasers Med Sci , 24(2), pp. 259-268. https://doi.org/10.1007/s10103-008-0539-1

Roo J. P. (1992) 'Permanent damage to inferior alveolar and lingual nerves during the removal of impacted mandibular third molars. Comparison of two methods of bone removal.', Br Dent J, 172(3), pp. 108-10 https://doi.org/10.1038/sj.bdj.4807777 
Tang E. and Arany P. (2013) Photobiomodulation and implants: implications for dentistry.J Periodontal Implant Sci, 43(6), pp. 262-268. https://doi.org/10.5051/jpis.2013.43.6.262

Trelles M.A. and Mayayo E. (1987) Bone fracture consolidates faster with low-power laser., Lasers Surg Med, 7(1), pp. 36-45. https://doi.org/10.1002/1sm.1900070107

Tunér J. and Beck-Kristensen, P. H. (2011) 'Low-Level Lasers in Dentistry', in Principles and Practice of Laser Dentistry. New York, USA: Mosby, Elsevier, pp. 263-286. https://doi.org/10.1016/ B978-0-323-06206-0.00015-1

Vescovi, P. et al. (2007) Nd:YAG laser biostimulation of bisphosphonate-associated necrosis of the jawbone with and without surgical treatment, Br 7 Oral Maxillofac Surg, 45(8), pp. 628-632. https:// doi.org/10.1016/j.bjoms.2007.03.016

Walsh L. J. (1997) The current status of low level laser therapy in dentistry. Part 1. Soft tissue applications., Aust Dent J, 42(4), pp. 247-254. https://doi.org/10.1111/j.1834-7819.1997. tb00129.x

\section{RESUMEN}

El uso de la terapia con láser de baja potencia (LLLT) en la reparación ósea se ha estudiado durante años y su aplicación en la implantología sigue siendo un tema controvertido, debido a la difícil evaluación de su eficacia clínica. Reportamos la aplicación de LLLT como ayuda en la osteointegración en dos pacientes sometidos a cirugía de implantes en el maxilar superior. En un hemi-arco se aplicó la LLLT y en el otro se utilizó como control. La evaluación del área ósea que rodea a las fijaciones se realizó mediante tomografía computarizada Cone Beam y el área de contacto hueso-implantes se midió mediante el software InVesalius ${ }^{\circledR}$. Los hallazgos radiológicos apoyan la idea de considerar la bioestimulación con láser como un coadyuvante en la cirugía de implantes.

Palabras clave: fotobioestimulación; odontología de implantes; terapia con láser. 